\title{
Purpose-Built Educational Computers in the 1980s: The Australian Experience
}

\author{
Arthur Tatnall $^{1}$ and Ralph Leonard ${ }^{2}$ \\ ${ }^{1}$ Graduate School of Business, Victoria University, Australia \\ Arthur.Tatnallevu.edu.au \\ ${ }^{2}$ Department of Further Education, Employment, \\ Science and Technology - Government of South Australia \\ Leonard.Ralphesaugov.sa.gov.au
}

\begin{abstract}
The first microcomputers were developed in the late 1970s and soon a wide variety of these machines were available for school and home use. This presented both a marvellous opportunity to improve school education and a significant problem for education authorities in how to provide support for the range of available computers. Several countries, including Australia, attempted to solve this problem by designing and building their own educational computer systems. This paper briefly describes how New Zealand, the UK and Canada designed and built computers for use in schools, and looks in more detail at how Australia started down this path and designed, but did not ultimately proceed to build an educational computer.
\end{abstract}

Keywords: History of educational computing, purpose-built school computers, Poly, Icon, Acorn, Microbee, Australian Commonwealth Schools Commission, National Computer Education Program.

\section{Introduction}

The widespread use of computers in schools is now commonplace, but this has only occurred in comparatively recent times, beginning in the late 1970s and early 1980s. Before this time a few Australian schools had some access to a mini-computer or used punch or mark-sense cards at a local university, but these schools were few in number. In an exception to this the Angle Park Computing Centre (APCC) in South Australia and the Elizabeth Computer Centre in Tasmania offered shared computing facilities to all schools in their respective states. The advent of relatively low cost microcomputers such as the Apple ][ and Tandy TRS-80 in the late 1970 marked the beginning of the growth of computers in schools. These early computers typically stored their software on audio cassettes as disk drives were not readily available and quite expensive until some years later.

An early problem was the diversity of available types of microcomputer, compounded by each Australian state controlling its own school education system. This meant that co-operation between the states was not to be taken for granted. One problem with using these early microcomputers in schools was that while you could show the students what a computer was, and even look at the electronics inside, you could 
not do much with them apart from programming and playing computer games as there was not much suitable software available for use in the school classroom. The states of South Australia, Tasmania and Western Australia did have support for development of software and set up the TASAWA consortium agreed to exchange software between these states. This is, perhaps, the first example of organised multi-state collaboration in computer education and the for-runner for the national program, but unfortunately the other Australian states were not parties to this consortium.

Another issue was cultural as what software there was often had an American outlook. An example of this was the simulation game 'Lemonade', available for the Apple ][ and based on making and selling lemonade from a street stall. While this had some merit in terms of teaching students about one aspect of doing business, lemonade stands are almost unknown in Australia. Another slightly later example is the 'Trash Can' on the Apple Macintosh. In Australia we use a 'Rubbish Bin'.

In the early 1980s the number of microcomputers on the market skyrocketed and education authorities started to see a potential infrastructure problem in servicing the schools that purchased these machines. All this presented both an educational need and a business opportunity and several countries decided to design and build their own school computers. They saw a solution to the educational need in writing their own educational software for these computers, and the business opportunity in having the new computers designed and built locally.

\section{Purpose-Built School Computers}

\subsection{Poly Computer (New Zealand)}

Probably the first microcomputer specifically designed for educational use was the Poly from New Zealand. The Poly was designed by Neil Scott and Paul Bryant at Wellington Polytechnic (hence its name) in 1980 as a teaching machine intended for computer assisted learning $[1,2]$. Scott and Bryant had recognised a niche market in the education centre and proceeded to exploit it [2] along with a team of engineers and technicians.

Poly-1 was a networkable machine based on the 6809 processor and came with $64 \mathrm{k}$ bytes of RAM [1]. The New Zealand government's Development Finance Corporation partnered with Progeni Computers [3] to form Polycorp. Poly was manufactured by Polycorp New Zealand, and became available in 1981. Polycorp had worked towards getting assistance from the New Zealand government, but this fell through. Polycorp worked with a number of New Zealand teachers to produce and refine courseware for a variety of teaching areas. The main problem with Poly was its cost of around $\$ 8000$ (NZ) which was considerably higher than competitors such as the Apple ][. Smythe [2] and Harpham [3] claim that the Poly computer was eighteen months ahead of the Acorn BBC Micro computer and with government support could have become highly significant on the world scene.

\subsection{Acorn BBC Computer (UK)}

The BBC Micro was designed and built by Acorn Computers in the early 1980s for use in the British Broadcasting Corporation's Computer Literacy Project [4]. The 
BBC had noted that with the availability of a growing number of powerful and increasingly less expensive microcomputers on the market, that it would soon be feasible for many people to purchase their own computer at an affordable price [5], and decided to start a computer literacy television series. The BBC needed a microcomputer capable of performing tasks which could be demonstrated in their TV series 'The Computer Programme'. These included: programming, graphics, sound and music, Teletext, controlling external hardware and artificial intelligence [4]. After discussions with several British computer companies, Acorn won the contract to provide a computer for this program and the Acorn Proton (successor of the Acorn Atom) became the Acorn BBC model A. The Acorn BBC model B followed in 1982 [5], based on a 6502 processor and with 32k bytes of RAM.

\subsection{ICON Computer (Canada)}

In 1981 the Ontario Minister of Education announced a need for computer literacy for all students and set up an Advisory Committee on Computers in Education that would, amongst other things, would draw up plans for an educational computer that would become the standard in Ontario schools [6]. A series of working sessions by various government departments and professional associations during 1981 produced a set of specifications for an educational computer. These included high resolution colour graphics and sound synthesis capabilities (which were only just possible at this time), 64k of RAM and a local area network form of architecture. By 1983 CEMCorp (later to join with Burroughs) had developed a prototype ICON computer to meet the Ministry's specifications. The ICON was quickly nicknamed the 'Bionic Beaver' and the first of these were installed in a few Ontario schools in 1984. The ICON system was designed around the 80186 microprocessor, based on a file server / workstation model with no local storage on the workstations [7] which were housed in a single box that included a keyboard and trackball. The operating system was Unix-like. The Ontario Ministry of Education sponsored the production of educational software and subsidised schools in purchasing their ICON computers from 1984.

\section{Designing the Australian Educational Computer}

In 1983, the Australian Government's Commonwealth Schools Commission set up the 'National Advisory Committee on Computers in Schools' (NACCS) to plan a National Computer Education Program. The terms of reference of this committee were to provide advice on professional development, curriculum development, software/courseware, hardware, evaluation, and support services [8]. In February 1984 the Commonwealth Minister for Education and Youth Affairs announced an \$18.7 million 3 year 'Computer Education Program' that would approach computer education in terms of a broad educational program, rather than simply as an exercise in hardware provision. Nevertheless computer hardware was an important consideration. The Committee believed that Schools Commission funds should be used for the purchase of computer hardware by schools, but as a substantial level of standardisation of equipment was necessary to achieve a balanced and effective National Computer Education Program this should be subject to strict guidelines. In the short term they recommended that Commonwealth 
funds be provided to support the purchase by schools of only BBC Acorn, Microbee 64, and Apple //e computers. This recommendation was later softened so that these funds could be used to purchase a computer on the 'recommended list' drawn up by any given state [9]. In the longer term however the need was seen for Australia to develop an educational computer system of its own.

"To meet the long term requirements of schools computing activities in Australia, it is considered essential to embark on a national research and development project that will ensure that appropriate computer systems are available. This ... will involve:

- the research and preparation of a set of Educational User Requirements. This is a statement of agreed educational needs to be met by the computer systems;

- the development of a set of Educational Technical Requirements based on the Educational User Requirements. This is a statement of the function, main features and performance required by the user for a system which can reasonably be expected to be available to satisfy the requirements in the planned time period;

- a System Concept Study which involves research and analysis of all practical alternatives to satisfy the Educational Technical Requirements. It includes consideration of development and production options and use of existing items either as they are or in modified form;

- if no existing items satisfy the Educational Technical Requirements, then a development proposal leading to the design and development of appropriate systems is required. [10:44]

The process by which this might be achieved is described in Appendix E of this report [10:69-72].

"The National Advisory Committee on Computers in Schools has recommended that the research, design and development process described below be adopted. This process would involve:

- Commonwealth Schools Commission co-ordination and funding of the research and development of educational requirement documentation and;

- Department of Science and Technology co-ordination and funding of computer equipment research, design and development.

Elements of the process are:

(a) Commonwealth Schools Commission leadership in the research of requirement document namely:

(1) An Educational User Requirement; and

(2) An Educational Technical Requirement.

(b) Department of Science and Technology leadership in equipment research, design and development through:

(1) A Systems Concept Study; and

(2) An Australian Design Specification including the design and manufacture of pilot and prototype systems if necessary. 
There were two principal reasons for wanting to develop an Australian Educational Computer: so that Australian school children would have access to suitable, well designed equipment; and to provide a development and manufacturing opportunity for Australian industry [11].

\subsection{Educational User Requirements}

An Educational User Requirement Working Party was appointed early in 1985, and soon provided an interim report outlining the many and varied educational needs of computer users in schools. The report began by considering educational assumptions underlying learning situations in primary and secondary schools, based on a statement from the Schools Commission report:
"The emphasis in efforts to integrate information technology in the cur- riculum should be placed on developing inquiry and problem-solving skills so that students can gain an understanding of the concepts, sym- bolic terms and language involved. In this way information technology will not be seen as applicable exclusively to any one curriculum area, but as a tool for establishing meaning and communication, for classify- ing and ordering data and experiences and for opening up new approaches to learning" [10:25]

They then listed learning situations in which computer use was considered appropriate, including: brainstorming, inquiry learning processes, 'dialectic' problem-solving, 'procedural/technical' problem-solving and process writing. They then went on to consider scenarios of activities and their organisation, including: classroom interest centres a primary school scenario; co-operative large group use; flexible and varied modes of classroom use; project group use; gathering, organising and analysing information; developing language skills; computer assisted learning; expert systems; using computers as a tool in existing subject areas; studying computer science; using computers in special education; whole school use of computers; and evaluation of learning [12]. The report then attempted to draw user requirements from each of these. For instance in the case of co-operative large group use:

"User requirements as a consequence of this large group of learners
reacting to a single monitor would include an emphasis on the need for
a large clear video display visible to all students in the group and the
use of colour, graphics and sound/music capabilities." [12:12]

In summary the report highlighted: the need for a common user interface, the need to consider a variety of user environments, the need for a modular compatible construction so that hardware and software can be added and subtracted later as required and a need for adoption of current recognised standards [12].

\subsection{Educational Technical Requirements}

Education in Australia is the responsibility of the State Governments, the Commonwealth's main role being in the co-ordination and funding of special projects. The Technical Requirement Working Party [13] was set up in 1985 as an 'expert' 
committee with membership reflecting the range of relevant groups and interests: David Woodrow (St Peter Luther College, Queensland), David Ashmore (Director, Information Technology, Department of Industry, Technology and Commerce), David Nicholls (Assistant Director, Information Technology, Department of Industry, Technology and Commerce), Paul Jenner (Senior Education Officer, Computer Education Unit, NSW Department of Education), Les Keedy (Newcastle University), Ralph Leonard (Co-ordinator of Computer Resources, Angle Park Computing Centre, South Australia), Jim Park (Head of Data Switching Networks, Telecom Australia Research Labs), Andy Quaine (Computer Science Department, Australian Defence Force Academy), Jim Sully (Superintendent of School Computing, Education Department of Western Australia, Arthur Tatnall (Educational Computer Systems Analyst, State Computer Education Centre, Ministry of Education, Victoria) and Steve Murray (Chief Education Officer, Computer Education Program, Commonwealth Schools Commission). The Committee met for a total of 18 days in the period June 1985 to March 1986, finally publishing its report in mid-1986.

\subsection{Recommendations}

The report has two main sections, one detailing the technical requirements and the other suggesting possible implementations [13]. In the requirements section the Committee endeavoured to keep things as general as possible and not to mention specific figures, such as 64k RAM, unless this was unavoidable. After almost 25 years this section still looks remarkably up to date.

It was considered that an implementation of these requirements would need to satisfy at least three types of use: personal, classroom and school-wide. The implementation guide suggested that these could be catered for by a family of compatible systems, having a common user interface [13], and that at some stage in the future the way should be left open to connect these systems to computing facilities at the district, regional, state or national levels.

\subsubsection{Personal Systems}

The system intended for individual use should be totally portable so that it could be used by students in a classroom at school, in the school grounds, at home, on the bus when travelling, or anywhere else required. It was considered likely that use by an individual student for word processing would be its major applications, but that it would also be used to perform applications such as use of spreadsheets, educational simulations and the manipulation of small databases. The personal system would need to be totally upward compatible with classroom and school systems $[8,11]$.

\subsubsection{Classroom Systems}

The computer systems normally used in the classroom need not be portable, but should still be able to be moved around within the school. They should be able to be configured to perform a much wider range of tasks that the Personal System, including all those currently asked of school computers. They should be easily expandable, possibly with plug-in cards or connection of external expansion units. 


\section{MODULES}
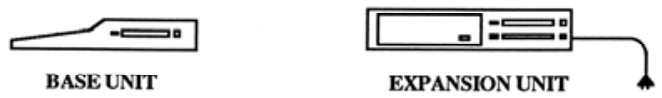

Fig. 1. Possible implementation using a Base Unit and an Expansion Unit
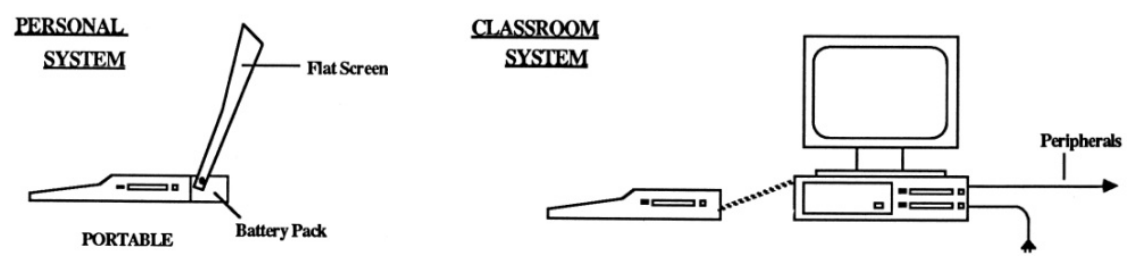

Fig. 2. Implementation linking a Personal System into a Classroom System

In one possible implementation, a Classroom System could be built up by adding appropriate extra components to a Personal System. The provision of normal (nonportable) colour monitors to which a Personal System could be connected would be one variant of this implementation.

Another implementation may include the attachment of an external expansion unit. Although not the only way this system could be implemented, the use of a common base unit which would also be the Personal System was one option $[8,11]$.

\subsubsection{School Systems}

School Systems would comprise a network to enable Personal and Classroom Systems to be connected to each other, and to devices such as printers, mass storage devices, special purpose peripherals, and remote computers [13]. A School System was envisaged to be a transparent system with a number of connection points in each classroom and around the school $[8,11]$ so that students could plug Personal Systems into connection points to use a printer or to up or down-load software or perhaps an assignment. A number of Classroom Systems could be connected to the School System to facilitate use of software, sharing of resources, and the sharing of common data. At any time the School System could be decomposed into its individual modules to form a number of Classroom and Personal Systems.

An educational computing scene envisaged for the future was one where each student would own a Personal System. These would be built on contract for the government and purchased, perhaps on a long term leasing basis, by individual students. Classroom and School systems would be purchased by schools using government funds. Students having constant access to a Personal Computer System would revolutionise the education system and make many of the dreams of computer educators possible. 


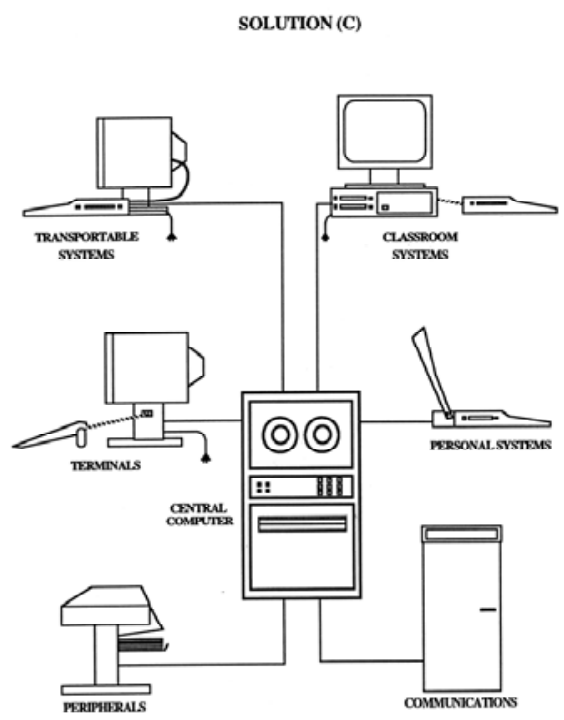

Fig. 3. One possible implementation of a School System

\subsection{Building the Recommended Educational Computer}

There were two principal reasons for wanting to develop an Australian Educational Computer: so that Australian school children would have access to well designed equipment and to provide a development and manufacturing opportunity for Australian industry. It was generally supposed that an Australian company such as Microbee, which produced a CP/M computer used in many Australian schools, would be a likely manufacturer. The next step in the process should have been the setting up of a System Concept Study to be followed by a Development Proposal, but at this stage the project ran out of steam, as the 3 year Government funding for the program was at an end and further funds were not made available. The System Concept Study and Development Proposal were thus not taken any further [8].

\section{Reflections on a School Computer That Was Never Built}

One of the strengths in the work undertaken to design Australian School Computer Systems was that the work of the Technical Requirement Working Party lay within a program that intended to be far-reaching. The News Release by the Minister for Education and Youth Affairs, announcing the \$18.7 million Computer Education Program on $19^{\text {th }}$ February 1984 , stated:

"We are going to approach computer education in terms of a broad educational program, rather than simply as an exercise in hardware provision. The central themes here are building a capacity to generate Australian content with sound educational values across a broad range 


\section{of school subjects; and developing a teacher force capable of using computers to the advantage of all children in school."}

Hence the design was driven by strong principles of usability in a wide range of educational contexts. The Technical Requirement Working Party was given instruction to be particularly forward thinking and

- "be guided by the user requirements and not restricted by available or predicted equipment, nor be unduly influenced by the current state of the art;

- take into account the relevant documents from the Australian States and overseas

- provide some indication of the relative priority that is attached to various technical characteristics, at the least indicating those which are essential, and those which are desirable but not essential." [13:1]

These instructions were matched by the selection of members of the Technical Requirement Working Party which was assembled with "detailed experience of the requirements of Australian states, detailed up-to-date technical expertise, and a good understanding of the future directions of computers in education”. [13:1]

The Working Party's recommendations, described in section 3.3 above, illustrate a successful outcome in looking beyond the existing state of the market during the project and separating the desirable elements of a school computer system into a set of modular components.

However, even as the Working Party was finalising its report, new entrants to the personal computer market were extending the state of the art and rapidly progressing beyond the recommendations. The Amiga computer was released in the latter half of 1985 and took the expectation of colour displays and graphic capability beyond what the Working Party had envisaged. Atari Corporation also produced a much enhanced Atari ST computer at about this time. Nevertheless, after a quarter of a century, many of the recommendations remain consistent with the current practices regarding choices of equipment for educational environments.

What might have happened if the project had continued to the planned consequent stages of Development Proposals, Australian Design Specification and finally procurement? That remains an intriguing "what if" question. Not long after the release of the recommendations in June 1986, the three year funding for the Commonwealth Schools Commission's Computer Education Program was up and the program was discontinued. After the funding made available in the triennium from 1984-1986 was used, no further funding was allocated in the following years. Had further funds been available it is likely that the project to design and built an Australian Educational Computer would have continued. But in the longer term, would this have been a good thing?

A problem faced in Canada with the Icon computer was that after the government had spent so much money on one particular educational computer the idea of looking at other alternatives was not an appealing one. In a sense, no matter how good it had been at the time, Canada was stuck until the early 1990s with what it had designed and built in the early 1980s. This would not have been a problem if the technology had been static or even if it had been evolving slowly, but at this time a number of major changes occurred to the microcomputer market. While in the early 1980s there 
had been a large number of microcomputers available and potentially useable in schools, by the second half of the decade two significant players had begun to emerge and to displace all the others: the Apple Macintosh and the IBM PC (and compatibles). It was not long after this that these were the only microcomputers to occupy a significant place in school education, particularly after the advent of the Windows operating system (on IBM compatible PCs). An important consequence of this was that pretty much all software development occurred only on one or other, or both, of these platforms.

Another major development was the growing dominance of 'application software' packages including a word processor, spreadsheet, presentation software, graphics package and database manager, exemplified by the increasing significance of Microsoft Office. The problem was that Microsoft Office was available only on the Macintosh and Windows platforms and not for other microcomputers. As it is unlikely that an Australian Educational Computer would have been built to use either of these operating systems, it may quickly have become a Neanderthal that, although worthwhile in its own right, could not evolve further in line with emerging trends. Would this have been the case? What if the Australian project had proceeded right through to manufacture? How would building such a computer have stimulated the Australian computer industry? These are more intriguing 'what if' questions to which we will now never know the answers.

\section{Conclusion}

From the late 1970 s to the mid 1980s several countries attempted to solve the problem of providing useful computer systems for their schools by designing and building their own Educational Computer Systems. This paper has briefly described the Poly from New Zealand, the Acorn BBC from the UK and the ICON computer from Canada. That Australia also started down this path to design and build its own educational computer, but did not complete the exercise, has been the subject of this paper.

In retrospect, was the Australian exercise a waste of time and money? We suggest that it was not a waste of time and money as some useful results emerged from this project. The reports published by the two working groups are of value, even today, as were the interstate connections forged during the process of researching and writing these reports. On the other hand, given the benefits of hindsight, we also suggest that it was probably a good thing that the project stopped after the Educational User Requirement and the Educational Technical Requirement working parties had completed their work and published their reports. It was probably a good thing that it did not continue to the stage of a Systems Concept Study, Australian Design Specification and manufacture of the computer. This, however, we will never know for certain.

\section{References}

1. Editorial, Executive's Fighting Pledge. Bits \& Bytes, New Zealand, pp. 13-15 (1982)

2. Smythe, M.: The Poly 1 Educational Computer. Kiwi Nuggets Forum 2007 (2007), http: / /www.creationz.co.nz/kiwinuggets / 2007/03/poly-1educational-computer_07.html (cited 2010) 
3. Harpham, P.: Poly and Progeni (2007),

http: //www.mail-archive.com/ada_list@list.waikato.ac.nz/ msg00266.html (cited 2010)

4. Wikipedia. BBC Micro (2009), http://en.wikipedia.org/wiki/BBC_Micro (cited 2010)

5. Graça, G.: Acorn BBC. Old Computers.Com (2009), http: / /www. old-computers. com/museum/computer. asp?c=29\&st=1 (cited 2010)

6. Goodson, I.F., Mangan, J.M.: The Genealogy of the ICON. In: Goodson, I.F., Mangan, J.M. (eds.) History, Context, and Qualitative Methods in the Study of Education, pp. 207-248. University of Western Ontario, Canada (1992)

7. Wikipedia. Unisys ICON (2009), http: / / en.wikipedia.org/wiki/Unisys_ICON (cited 2010)

8. Tatnall, A.: Designing the Australian Educational Computer. Education 110(4), 453-456 (1990)

9. Tatnall, A., Jenner, P.: How State Education Authorities Recommend Computer Systems for Use in Australian Schools. In: Australian Computer Conference (ACC 1986). Australian Computer Society, Gold Coast (1986)

10. Commonwealth Schools Commission, Teaching, Learning and Computers. Report of the National Advisory Committee on Computers in Schools. Commonwealth Schools Commission, Canberra (1983)

11. Tatnall, A.: The Growth of Educational Computing in Australia. In: Goodson, I.F., Mangan, J.M. (eds.) History, Context, and Qualitative Methods in the Study of Education, pp. 207-248. University of Western Ontario, Canada (1992)

12. Commonwealth Schools Commission, Australian School Computer Systems: Educational User Requirements. Commonwealth Schools Commission, Canberra (1986)

13. Commonwealth Schools Commission, Australian School Computer Systems: Technical Requirements. Commonwealth Schools Commission, Canberra (1986) 